\title{
Gaining Legitimacy, Knowledge Creation and Hospital Survival
}

Chen-Wei Yang ${ }^{1}$, Shih-Chieh Fang ${ }^{2}$, Yu-Hua Yan ${ }^{3 *}$, Ching-Ying Huang ${ }^{2}$

${ }^{1}$ Department of Health Business Administration, Fooyin University, Taiwan

${ }^{2}$ Department of Business Administration, National Cheng Kung University, Taiwan

${ }^{3}$ Tainan Municipal Hospital and Chia Nan, University of Pharmacy and Science, Taiwan

Article Details
Article Type: Research Article
Received date: $03^{\text {rd }}$ August, 2017
Accepted date: $09^{\text {th }}$ October, 2017
Published date: $15^{\text {th }}$ October, 2017

${ }^{*}$ Corresponding Author: Yu-Hua Yan, Senior Specialist, Tainan Municipal Hospital and Adjunct Associate Professor at Chia Nan University of Pharmacy and Science, Taiwan. E-mail: anne@mail.tmh.org.tw

Citation: Yang CW, Fang SC, Yan YH, Huang CY (2017) Gaining Legitimacy, Knowledge Creation and Hospital Survival. J Pub Health Issue Pract 1: 102. https://doi.org/10.33790/jphip1100102.

Copyright: $\mathbb{0} 2017$, This is an open-access article distributed under the terms of the Creative Commons Attribution License 4.0, which permits unrestricted use, distribution, and reproduction in any medium, provided the original author and source are credited.

\begin{abstract}
There are three purposes of this study: (1) to examine the legitimacy gaining model (the relationship between legitimation strategies and legitimacy) in the context of hospital industry, (2) to explore the influence of legitimacy gaining model on the process through which knowledge is created within hospital industry. (3) to explore the impact of hospital organizations' knowledge creation on hospital survival .This paper proposes an legitimacy gaining model as the determinants of hospitals' knowledge creation activities. Then we argue that the legitimation model of knowledge creation will further influence the survival chance of hospitals. We further suggest the managerial implication and theoretical implication at the end of this paper. The main managerial implication is that to comprehend the legitimacy- gaining model of legitimation strategies and legitimacy elements may help hospitals' managers to make effective strategies to create new, innovative knowledge and identify useful legitimacy factors, which may both assist and impede the creation of knowledge. The main contributions to organization theory are that we combine the perspectives of institutional theory and knowledge creation theory and explicate the relationship of these two concepts in the studies of health care management field.
\end{abstract}

Key words: Legitimacy; Institutional theory; Knowledge creation; Hospital survival

\section{Introduction}

Hospital organizations are facing surprisingly complex challenges, including new treatment and diagnostic tech- nologies, ongoing pressures for health care institutional reform, the emergence of new organizational gover- nance structure and knowledge creation for health care system [1-3]. Under such situation, in the search to realize knowledge creation and survival of hospitals, legitimacy acts an important role. Legitimacy is usefully conceived as not merely another resource to be exchanged or possessed but a condition reflecting the alignment of an organization to normative, regulatory, and cultural-cognitive beliefs and rules prevailing in its social environment [4]. The degree of a hospital is judged to conform to legal rules, to standardized procedures, and to taken-for-granted how things are done has critical implications for the amount of support and sanction conferred through its environment, and thus for its survival $[5,6]$. However, we argue that legitimacy is a resource for hospitals as important as other resources like networks, financial capital, and technology, personnel and customer goodwill. Some researchers have recognized the importance of legitimacy for hospital survival.

The results of Ruef, et al. [7] empirical study show that both the managerial legitimacy and technical legitimacy provide notable improvements in hospital survival chances but the strength of each effect varies over time de- pending on the nature of the institutional environment. Scott, et al. [6] argue that three facets of legitimacynor- mative, regulative and cognitive - were found to affect hospital survival rates. Wells, et al. [8] propose how legit- imating ties may buffer hospital against threats to survival. Alexander, et al. [9] also argue that legitimacy signals worthiness for receiving societal resources necessary for survival in health care sector. However, these studies do not clarify how the hospitals gaining legitimacy they need to survival. In order to illuminate the legitimacy building process, we explore how the hospitals acquire legitimacy through legitimation strategies in this paper.

According to Zimmerman, et al.[10], legitimacy is an important resource for gain other resource, such as intellectual or knowledge resource, and such resource are crucial for organizational survival. Despite the critical role of legitimacy as the determinants for hospital survival, we argue that knowledge acts as another substantial resource for hospital survival. The importance of knowledge as a key source of competitive advantage is now well established in management studies, as suggested by the growing literature focusing on knowledge creation [10-12]. According to knowledge-based view $[11,14]$, a firm's competitive advantage is rooted in its own knowledge and those that it can obtain. The health care organization's codified knowledge (i.e., knowledge that can be easily communicated, structured, and identified) and its tacit knowledge (i.e., knowledge that is rooted in hospital's process, routines and culture) that create the competitive advantage affect the quality care improvement and effective health service in health care sector [2]. Although legitimacy identified as important issue organization face [15] and although concept of legitimacy has been applied to health care management issue [6-8], relatively few research study the relationship between legitimacy and knowledge creation in health care context. However, the other aim of this paper is to explore the relationships between legitimacy gaining process and the knowledge creation performance within hospital industry. 
In this paper, we propose three types of legitimation strategies (conform to environment, select environment and manipulate environment) as the strategic actions of hospital to acquire legitimacy (normative, regulative and cognitive legitimacy) in health care sector. Furthermore, we emphasize that legitimacy is a resource important for knowledge creation activity of hospital organizations. Finally, knowledge creation performance will further enhance the chance of hospital survival. The central arguments of this paper are to enhance our understanding of the impact of legitimation strategies determinants on the legitimacy building process for hospital organizations and to understand the influence of legitimacy on hospital organizations' knowledge creation performance and their survival chance.

In summary, there are three specific research questions in this study:

1. What is the influence of the legitimation strategies that may impact hospital organizations' legitimacy gaining process?

2. What is the relationship between legitimacy gaining process and hospital organizations' knowledge creation performance?

3. What is the impact of hospital organizations' knowledge creation on hospital survival?

\section{Theoretical Background}

\section{Gaining Legitimacy}

Legitimation strategies: Because organizational legitimacy is so important to hospital survival, what we concern is that how hospital can acquire legitimacy. Legitimacy was seen as something operating mainly at preconscious or subconscious level, so there are less chance for organization to aware of it and to use deliberate strategies to manipulate it $[16,17]$. Some studies about legitimacy suggest that organization can apply strategic choice to alter the amount and type of legitimacy they have $[4,10,16,18]$. According to Suchman, et al. $[10,16]$, they propose the concept of legitimation strategies as the strategic action for organization to gain legitimacy. The term legitimation, rather than legitimacy, indicates that it is a process. Thus, we adopt legitimation strategies into the field of health care management studies.

Legitimacy building is generally a proactive action, because managers of hospital have advance knowl- edge of the need and of the plan for legitimation. Generally, legitimation strategies fall into three clusters: (a) Conformance: efforts to conform to the dictates of preexisting audiences within the organization's current environment, (b) Selection: efforts to select among multiple environments in pursuit of an audience that will support current practices, and (c) Manipulation: efforts to manipulate environmental structure by creating new audience and new legitimating beliefs $[10,16]$. The three strategies involve complex mixtures of persuasive organization communication and concrete organizational change [20]; however, the logic of these strategies falls along a continuum from relative active manipulation to relatively passive conformity [21].

Conformance Strategies: Conformance indicates acquiring legitimacy by reaching conformity with the expectation and need of existing social structure in which the organization is currently placed $[10,22,23]$. A hospital that conforms does not question or violate the structure of health care sector. Hospitals acquire legitimacy by following the health policy. Conformance is an appropriate strategy for a hospital operating in a well-established health care sector where rules, norms, value and model taken for granted. For example, in 1983, the perspective payment system changed the payment structure from cost-based to prospective payment. This change was coercive because hospitals must conform to the system if they wanted to be reimbursed for the care of any Medicare patient.

Selection strategies: Selection of the environment involves some level of conformity to the environment but allows the organization to select in which it operates [10]. For the hospital, selection allows for the choice of a health care market that is most advantageous and consistent with the hospital. When the models, rules, values, norms and scripts of the health care environment are known and the hospital has the resource and the opportunity to select those most advantageous and consistent with it, selection can be an appropriate strategy. For instance, the hospital can select a benchmark to learn its successful management skill that is most advantageous or consistent with it. Such as the adoption of TQM and CQI technique can be seen as an example of selection strategy. These pressures stems from the need to find a way when facing uncertainty. In order to reduce the uncertainty, to select and mimic what other successful organizations have done is an easier way for hospitals [24].

Manipulation strategies: Manipulation involves making change in the environment to achieve consistency be- tween the organization and its environment [10]. Manipulation also involves preventive intervention to develop bases of support specially modified to the distinctive needs of the organization [16]. Manipulation strategies indicate more change to the environment than do conformance and selection. For example, a single hospital lacks the resource or power to manipulate its environment [23, 25]. However, a hospital can cooperate with successful, well-established hospital or hospital association such as American Hospital Association (AHA) to manipulate its health care environment. They can work together to lobby for legislative change in health policy or payment system impeding their survival.

The Elements of Legitimacy: If organizations are to thrive and survive in their social environment, they require more than technical information and material resources. They also need social credibility and acceptability [6]. Sociologists use the concept of legitimacy to these conditions. They view legitimacy as a social judgment of appropriateness, desirability and acceptance. Suchman, et al. [16] provides a useful definition of legitimacy as "a generalized perception or assumption that the actions of an entity are desirable, proper, or appropriate within some socially constructed system of norms, values, beliefs, and definitions". Legitimacy is also defined as congruency between norms, value, and expectations of society and the outcome and the activity of organization [26].

In this paper, we employ [4] categories of legitimacy that are regulative, normative, and cognitive elements, we can see that each presents a different basis for legitimacy. (a) The regulative legitimacy focuses on confor- mity to rules and the exercise of penalties: legitimacy as legally sanctioned behavior. Purchasing groups and governmental agencies are most likely to emphasize regulative elements, exerting rewards and sanctions and legal authority to exercise control. (b) The normative legitimacy emphasizes internalization of and compliance with collective values and norms: legitimacy as morally governed behavior. Professional associations are likely to emphasize normative controls and elements. Hospital organizations in healthcare systems rely on both regu- lative and normative controls over their component units. (c) The cognitive legitimacy stresses consistency with cultural-cognitive models and schemas: legitimacy as take-for-granted structure and behavior. All legitimating agents as well as broader frameworks of widely shared cultural belief promulgate and enforce cognitive rules (schemas, typification, classifications, concepts) [6].

Regulative legitimacy: The regulative component of institutions emphasizes on explicit rule setting, sanction- ing, and monitoring by a supervising body seizing power or authority over relevant actors [4]. Such activities are often lodged in formal oversight structures, such as state agencies, but private bodies can also exercise them. For example, trade associations that enforce fair trade agreements that exercise power over subsidiary units. The em- pirical study of [27] indicated a figure of regulatory when they examined whether voluntary social service orga- nizations in Toronto gained a charitable registration number from the state agency, Revenue Canada. In hospital industry, a wide range of regulatory programs exists, and different healthcare organizations are subject to various oversight 
authorities. In United States, The regulatory programs were those involved in licensing of healthcare personnel at state level among the earliest public regulatory activities initiated in the medical care field. Other activities, involving both federal agencies and state, include health planning and rate setting [6]. However, there exist many sources of regulative legitimacy over hospitals, include labor law, common law (duties and responsibilities of corporate officials, negligence and liability, the hospital's contractual agreements), monitoring of financial operations, personnel licensure and hospital licensure [7].

Normative legitimacy: The normative legitimacy, stressed by Weber's idea of administrative systems, focus on "normative rules that introduce a prescriptive, evaluative, and obligatory dimension into social life"[4]. DiMaggio, et al. [25] suggested that organizations are subject to the request of generalized societal norms such as fair play but are mainly constrained by the existence of a variety of professional and occupational standards to which participants subscribe. In the healthcare field in the US, normative legitimacy has long been subject to strong professional norms, as evidenced by the authority of organizations such as the American Medical Association (AHA) and American Medical Association (AMA). In hospital industry, where outcomes are often difficult to assess and uncertain, professional associations build up "to collectively create and maintain institutional legitimating devices' that increase public trust [28]. These associations engage in systematic and regular efforts to evaluate the conformity of hospital organizations to industry wide professional standards and to provide assurance to the public that such matters receive careful scrutiny. Hospitals receiving favorable evaluations are likely to exhibit them openly to relevant audiences; on the other hand, the failure of accreditation is broadly publicized in local or even national media [7].

Cognitive legitimacy: Cognitive legitimacy means the rules that indicate what types of actors are allowed to exist, what procedures they can follow, what structural features they display, and what meaning are related to these actions. Therefore, cognitive legitimacy offers frameworks on which normative and regulative legitimacy are constructed and is more basic to the operation of social systems [7]. The "new" institutionalism has stressed the crucial roles of these cognitive elements of institutions [23,25,29,30] employ organizational density as an indirect indicator of cognitive legitimacy. They suggest that the prevalence of a given organizational form-the numbers of organization's adopting a given form-provides a useful measure of the "taken-for-grantedness" of that form in a given field. In the perspective of hospital industry, hospitals are a takenfor-granted arrangement for providing healthcare services, and individual organizations rarely depart from the conventional format or archetypes.

Knowledge Creation: As to the meaning of organizational knowledge creation, it indicates that to transform individual skill into knowledge embedded in organization via appropriate transformation mechanisms. Nonaka, et al. [13] called it "knowledge spiral", the processes include four stages: socialization, combination, externalization and inter- nalization. Nonaka et al. [31] further indicated that the establishment of $\mathrm{Ba}$, the inter-transformation process of implicit knowledge and explicit knowledge and the storage of organizational existing knowledge as three im- portant factors to decide the performance of knowledge creation. Hedlund [32] also had similar perspectives; he assumed that organizations could create unique organizational knowledge via absorption, imitation, digestion, and application. Besides, Grant et al. [11, 14, 33, 34] pointed out that organization could recombine existing knowledge or new knowledge to be knowledgeable asset of organization via integration and learning. In sum- mary, this study defines knowledge creation as that it is the processes of which the individuals or divisions of the organization implement the given task or solve the specific problem and/or then recombine and transform ex- ternal new knowledge to further establish new organizational knowledge via retrieving the required knowledge in existing knowledge base. Therefore, the final outcome of the knowledge creation process contributes to the increase of both quality and quantity of health care organization's existing knowledge base.

Lemieux-Charles, et al. [2] using Nonaka's knowledge creation theory (1994) to explore how health care net- works facilitate the creation of knowledge. This study suggests that effective health services rely on a foundation of research-based evidence and that the quality care improvements in health care organizations are dependent on the application of evidence. Hence, Nonaka's theory of collective knowledge creation provided a useful frame- work for researchers to explore knowledge creation process within health care sector.

In this paper, we emphasize three types of legitimation strategies (conformance, selection and manipulation) by Suchman [16]. This study takes these legitimation strategies as three types of strategic actions that hospital managers should adopt for gaining legitimacy in hospital industry. Using appropriate legitimation strategies should be helpful for hospital to gain legitimacy. According to Scott's [4] perspective, we categorize legitimacy as regulative, normative, and cognitive elements. Legitimacy is an important resource for gaining other resources and knowledge [10]. Institutional theory emphasizes that institutional pressures, sometimes coming from external sources, other times coming from within the organization itself, will influence organizations. Under some conditions, these pressures lead organization to be guided by legitimacy. Adoption of legitimacy, leading to isomorphism with the institutional environment, increases the survival chances $[35,36]$ suggest that if isomorphism results in organizational change, it is the result of some form of knowledge process. Change requires both explicit knowledge and tacit knowledge. The isomorphism mechanism suggests there may be some influence on what and how organization learn and create knowledge. However, this study suggests the legitimacy-gaining model should influence the hospital's knowledge creation performance.

The performance of knowledge creation means the accelerating increment of knowledge storage through recombination of existing $[31,37,38]$. Besides, according to Kogut et al. [11, 39] they assumed that organization create more organizational knowledge (intellectual capital) through knowledge exchange and combination. Therefore, this study will take the increment of knowledge asset and the elevation of ability of knowledge combination as the index of performance in knowledge creation measurement. Knowledge asset means health care managerial knowledge, productive and service knowledge, market and marketing knowledge and technical knowledge of health acre organization in this study. We also take effectiveness, broadness and flexibility to measure combination ability of knowledge according to the perspectives of De Boer, et al. [11, 14, 33].

\section{Hospital Survival}

Institutional theory stresses the importance of legitimacy in determining the fate of organizations. Legitimacy is achieved by conforming the organization's practice and formal structure to institutionalized values and beliefs. Hence, the organization demonstrates that it is acting in a adequate and proper manner, thus increasing its recognition and preventing concerns about its conduct by other social actors-e.g., regulatory agencies, consumer and suppliers [20,23]. In hospital industry, all hospitals have the chance to seek legitimacy to create useful knowledge from a variety of external normative sources. Some of them emphasize more on technical procedures, some on managerial procedures, and some pertain to both. Hospital organizations improve their survival chances insofar as they are successful in gaining legitimacy to create knowledge from such normative sources as American Hospital Association (AHA) or the Joint Commission on the Accreditation of Healthcare Organization (JCAHO) in US. 


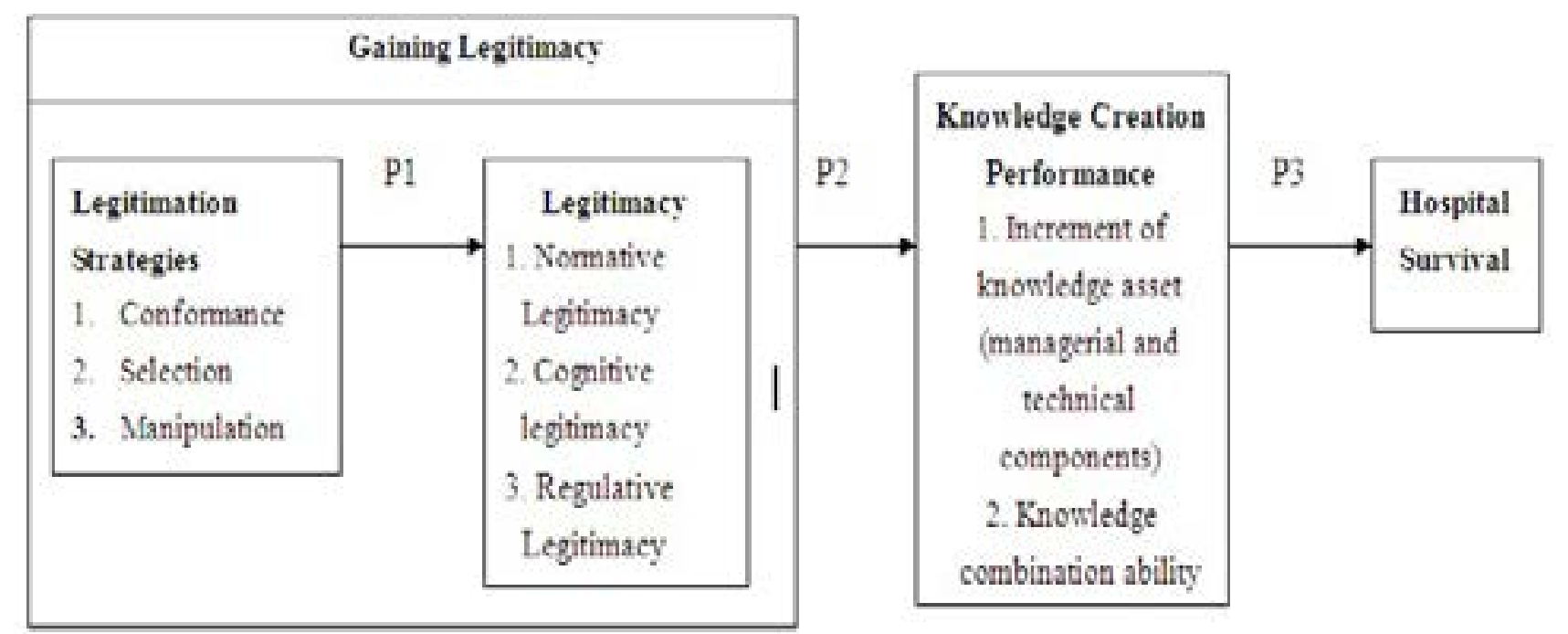

Figure 1:Conceptual Framework" summarizes the relationships proposed here among Gaining legtimacy (legitimation strategies, legitimacy), knowledge creation performance and hospital survival.

\section{Developmentof Proposition}

\section{The Model of Gaining Legitimacy}

Since the concept of legitimacy derived mainly from institutional theory [41], we view legitimacy as consistency of organizational goals with societal functions, social judgments of acceptance, appropriateness. Scott, et al. [4] determined the legitimacy into three basic elements - the normative legitimacy, the regulative legitimacy, and the cognitive legitimacy. Each construct has its distinction for researcher to evaluate the concept of legitima- cy. Given the importance of legitimacy for the chance of hospital survival, we need to realize how hospital can gain legitimacy.

The earlier institutional theorists argued that organizations "received" legitimacy by conforming to system-wide rules, norms, and beliefs $[4,23,41,42]$, but they explained little about the legitimacy gaining process. Recent studies about legitimacy suggest that organizations can exercise strategic action to alter the type and amount of legitimacy they possess [4, 18]. Child, et al. [16, 43] suggests that strategic action is the selection of performance standards within which one will operate and the manipulation of environment. Schuman [16] proposed that organizations can gain, maintain and repairing legitimacy through strategic approaches such as conformance, selection and manipulation. Furthermore, like most cultural process, legitimacy management (gaining,maintaining and repairing legitimacy) depends heavily on communicationcommunication between the organization and its various audiences [44,45]. Zimmerman, et al. [10] further establishes a legitimacy process model, which demon- strates that "legitimacy can be enhanced by the strategic actions of new venture". They also adopted four legit- imation strategies (conformance, selection, manipulation and selection) for acquiring legitimacy. Accordingly, we adopt the concept of legitimation strategies and legitimacy elements into the health care management studies and further follow the logic of legitimacy process model provided by Zimmerman, et al. [10]. We also suggest communication as the main mechanism during the legitimation process. Therefore, in the context of hospital industry, we develop proposition 1:

Proposition 1: A hospital can take strategic action to increase visible consistency with the health care environment by conforming to, selecting and manipulating the health care environment in which it exists.

J Pub Health Issue Pract

Volume 1. 2017. 102

\section{Gaining Legitimacy and Knowledge Creation}

DiMaggio, et al. [25] identified three types of institutional isomorphism: coercive, normative and mimetic. Institutional theorists emphasize more on the state (coercive isomorphism) and professional associations (normative isomorphism) in an organization's institutional context and their potentially influence in shaping an organization's legitimacy and performance [46]. We assume that institutional context exerts these isomorphic institutional pressures that result in isomorphism of hospitals. Hospitals will adopt appropriate legitimation strategies to help them achieve legitimacy in health care setting under such isomorphic pressures. Gaining the legitimacy resource is an essential way for organizations to get other resources, such as knowledge, financial and intellectual resources [10]. However, this study suggests that the hospital's organizational change, which result from isomorphism, can be seen as the result of some form of knowledge process. Organizational changes need both explicit knowledge and tacit knowledge to operate the knowledge creation process [47]. The isomorphism mechanisms advise that there may be some influence on what and how organization learn and create knowledge. Coercive isomorphism implies that some for of knowledge creation are involuntary. The acquisition of knowledge to enable knowledge creation to ensure the health care organization fit its changed institutional environment if the health care organization can maintain its legitimacy [48]. Normative or mimetic isomorphism results from voluntary learning and knowledge creation. Voluntary isomorphism implies that learning and knowledge creation depends on profession agent. Such professional agents bring to the health care organizations a body of knowledge that changes as the profession change. These professionals, with their access to external knowledge [49], provide opportunities for the hospital to create knowledge. However, Robertson, et al. [50] also suggests that the institutional effects will influence knowledge creation process within professional service firms.

From an institutional perspective, we argue that the institutional isomorphism acting as the mechanism in the legitimacy gaining model of knowledge creation can be seen as a knowledge creation process. This study suggests that the performance of hospital's gaining legitimacy model is "knowledge creation performance". Therefore, we argue that the legitimacy gaining model which the 
integrated the concepts of legitimation strategies and legitimacy elements will increase the performance of hospital's knowledge creation. Owing to the reasons above, in hospital industry, we suggest proposition 2:

Proposition 2: The well-established legitimacy gained by legitinmation strategies (conformance, selection and manipulation) will increase hospital's knowledge creation performance.

\section{The Legitimation Model of Knowledge Creation and Hospital} Survival

Hospitals operate in highly institutionalized environments that put considerable pressures on both their man- agerial and technical component. Tompson, et al. [51] suggests three levels within organizations: (1) a technical level, which responsible for transforming production inputs into outputs, (2) a managerial level, which acquires and administers essential resources for technical production system, and (3) an institutional level, which connect an organization to its environment and attempt to protect its legitimacy. Accordingly, we suggest that legitima- tion efforts by healthcare officials at institutional level can be focus on either the technical level or the managerial level, or both. From the hospital's side, it is really important to gain legitimacy for knowledge creation both in managerial and technical level. Managerial knowledge creation involves the knowledge of personnel manage- ment, accounting practices, and the rules of conduct and structure of the administrative staff. In US, managerial legitimacy of hospitals is typically conferred through outsight bodies (e.g., the American Hospital Association) that review the functions and structure of governance boards and administrator hierarchies. On the other hand, technical knowledge creation emphasizes normative support for the knowledge of staff qualifications, training programs, quality assurance mechanisms and work procedures. The assessment of technical legitimacy revolves around patient-centered task, such as treatment, diagnosis, education and continuum, as well as ethical issues concerning patient rights [52].

The hospitals have the chance to gain legitimacy for creating managerial or technical knowledge from a variety of external normative sources. Myer, et al. [53,54] have argued that organizations running in highly institution- alized environments are more likely to survive to the extent that they are successful in obtaining legitimacy from those normative sources that are in a position to approve or disapprove their programs, staffing and structures and than influence their knowledge creation chance and performance. Hence, hospital organizations can in- crease their survival chances insofar they are successful in gaining legitimacy for knowledge creation activity from normative sources as the Joint Commission on the Accreditation of Healthcare Organizations (JCAHO) or the American Hospital Association (AHA) [7]. In summary, legitimacy gaining and knowledge creation may increase a hospital's survival because legitimacy enhances other organizations' willing to grant the hospital critical resources, such as managerial or technical knowledge. Particularly when there is little basis on which to evaluate the hospital's reputation and care quality. Owing to the reasons above, in hospital industry, we suggest proposition 3:

Proposition 3: The higher level of hospital's knowledge creation performance will earn itself higher survival chance.

\section{Discussion and Conclusion}

Scott [52] suggested a valuable summary of institutional theory. Powell, et al. [41] charted the further changes. While many constructs of institutional theory have developed, the study of various institutional environments to which organizations must respond has been particularly helpful for realizing such change in hospital industry.

There are three purposes of this study: (1) to explore the legitimacy gaining model (the relationship between legitimation strategies and legitimacy) in the context of hospital industry, (2) to explore the influence of legitimacy gaining model on the process through which knowledge is created within hospital industry. (3) to explore the impact of hospital organizations' knowledge creation on hospital survival. We propose a legitimacy-gaining model as the determinants of hospitals' knowledge creation activities. Then we argue that the legitimation model of knowledge creation will further influence the survival chance of hospitals. Institutional theory perspectives of legitimacy elements and legitimation strategies may provide a new understanding to hospital seeking effective knowledge creation strategies within highly institutionalized environment of health care sector and to enhance the survival chance of hospitals. We further suggest the managerial implication and theoretical implication below.

\section{Managerial Implication}

This paper suggests two implications for management practice. First, although further empirical study is needed, it beginning to appear that comprehending the legitimacy gaining model of legitimation strategies and legitimacy elements may help hospitals' managers to make effective strategies to create new, innovative knowledge and identify useful legitimacy factors, which may both assist and impede the creation of knowledge. Second, we also suggest the importance of contingency approach to hospitals' manager that hospitals' legitimation strategies choice tailors hospitals' structure to the source of uncertainty that hospitals face. The legitimation strategies are selected by the hospital to respond various contingencies in institutional environment to acquire high level of legitimacy.

\section{Theoretical Implication}

Three are two theoretical contributions of this paper. First, in order to examine the impact of institutional context on hospital survival, we combine the idea of [10] legitimacy process model and Suchman [16] legitimation strategies and apply them into the study of health care management. Second, we integrate the perspectives of institutional theory and knowledge creation theory to establish a legitimation model of knowledge creation and explicate its influence on hospital survival. In summary, we provide a conceptual application of institutional theory and knowledge creation theory in health care organization. In other words, this study proposes a model to explicate the relationship between legitimation strategies, legitimacy, their knowledge creation consequence and hospital survival within hospital industry. Based on the theoretical foundation and the reasoning logic in this paper, we may examine the institutional process and its influence on hospitals' knowledge creation and survival empirically in the further study.

This study highlights the value of combing the institutional theory logic with the knowledge creation theory logic in the application of health care management studies. Furthermore, the strategic approach emphasizes that the model of legitimacy gaining and their consequence will further enhance hospitals' knowledge creation performance and will increase their survival chance. However, in order to provide a constructive explanation for knowledge creation issue of hospital industry within institutional context, further empirical research and literature review is required.

\section{Acknowledgements}

This research was funded by Ministry of Science and Technology (MOST) in Taiwan (NSC 94-2914-I-242-006-A1 ). The earlier version of this paper was presented at the 2005 annual Academy of Management meeting in Honolulu, Hawaii, U.S.A. We thank three anonymous reviewers for their helpful comments.

\section{Conflict of Interest}

The author declares no conflict of interest 


\section{References}

1. Galvin TL (2002) Examining institutional change: Evidence from the founding dynamics of U.S. health care interest associations. Acad Management J 45: 673-696.

2. Lemieux-Charles L, McGuire W, Blidner I (2002) Building interorganizational knowledge for evidence-based health system change. Health Care Manag Review 27: 48-59.

3. Short JC, Palmer TB, Ketchen Jr. DJ (2002) Resource-based and strategic group influences on hospital performance. Health Care Manag Review 27: 7-17.

4. Scott WR (1995) Institutions and Organizations. Thousand Oaks Sage.

5. Alexander J, Kaluzuny A, Middleton S (1986) Organizational growth, survival and death in the US hospital industry: a population ecology perspective. Social Sci Med 22: 303-308.

6. Scott WR, Ruef M, Mendel RJ, Caronna CA (2000) Institutional Change and Healthcare Organizations: From Professional Dominance to Managed Care. Chicago: University of Chicago Press.

7. Ruef M, Scott WR (1998) A Multidimensional Model of Organizational Legitimacy: Hospital Survival in Changing Institutional Environments. Administrative Science Quarterly 43: 877-904.

8. Wells R, Lee SYD, Alexander JA (2001) Institutionalized ties and corporate social capital: The case of hospital merges and closure. In :Gabbay SM and Leender RT. Social Capital of Organization, Oxford, UK: Elsevier Science: 59-82.

9. Alexander J, D'aunno TA (2003) Alternative perspectives on institutional and market relationships in the U.S. health care sector. In S.S. Mick \& M.E. Wyttenbach (Eds.), Advances in health care organization theory: 45-78. San Francisco, CA. Jossey-Bass.

10. Zimmerman M, Zeitz G (2002) Beyond survival: Achieving new venture growth by building legitimacy. Acad Manag Review 27: 414-431.

11. Kogut B, Zander U (1992) Knowledge of the firm, combinative capabilities, and replication of technology. Organization Sci 3: 383-397.

12. Nonaka I, Nishiguchi T (2000) Knowledge Emergence: Social, Technical, \& Evolutionary Dimensions of Knowledge Creation, New York: Oxford University Press.

13. Nonaka I, Takeuchi H (1995) The knowledge-creating company, Oxford University Press: Oxford.

14. Grant RM (1996) Prospering in dynamically competitive environments: organizational capability as knowledge integration. Organization Sci 7: 375-387.

15. Hunt CS, Aldrich HE (1996) Why even Rodney Danger-field has a home page: Legitimizing the world wide web as a medium for commercial endeavors. Paper presented at the annual meeting on the Academy of Management, Cincinnati, $\mathrm{OH}$.

16. Suchman MC (1995) Managing legitimacy: Strategic and institutionalapproaches. Academy of Manag Review 20:571-610.

17. Mezias SJ (1995) Using institutional theory to understand forprofit sectors: The case of financial reporting standards. In W.R. Scott \& S. Christensen (Eds.). The institutional construction of organizations: 164-196. Thousand Oaks, CA: Sage.

18. Deeds DL, Mang PY, Frandsen M (1997) The quest for legitimacy: A study of biotechnology IPO's. Paper presented at the annual meeting of the Academy of Management, Boston.

J Pub Health Issue Pract

Volume 1.2017. 102
19. Luke RD, Walston SL (2003) Strategy in institutional environment: Lessons learned from the 1990s "Revolution" in health care. In Mick SS \& Wyttenbach ME (Eds.), Advances in health care organization theory: 289-324. San Francisco, CA. Jossey-Bass.

20. Dowling J, Pfeffer J (1975) Organizational legitimacy: Social values and organizational behavior. Pacific Sociol Review 18: 122-136.

21. Oliver C (1991) Strategic responses to institutional process. Academy Manag Review 16: 145-179.

22. DiMaggio PJ (1988) Interest and agency in institutional theory. In L.G. Zucker(Ed.), Institutional patterns and organizations: culture and environment: 3-22. Cambridge, MA: Ballinger.

23. Meyer JW, Rowan B (1977) Institutional organizations: formal structure as myth and ceremony. Admin Sci Quart 5: 583-601.

24. Flood AB, Fennel ML (1995) Through the lens of organizational sociology: The role of organizational theory and research in conceptualizing and examining our health care system. J Health Social Behav 154-169.

25. DiMaggio PJ, Powell WW (1983) The iron cage revisited: institutional isomorphism and collective rationality in organizational fields. Am Soc Rev 48: 147-160.

26. Ashforth BE, Gibbs BW (1990) The double-edge of organizational legitimation. Organiz Sci 1: 177-194.

27. Singh JV, Tucker DJ, House AG (1986) Organizational legitimacy and the liability of newness. Admin Sci Quart 31: 171-193.

28. Van de Ven A, Garud R (1989) A framework for understanding the emergence of new industries. In Richard Rosenbloom (ed.), Research on Technological Innovation, Management and Policy, 4: 195-225.

29. Zucker LG (1977) The role of institutionalization in cultural persistence. Am Sociol Rev 42: 726-743.

30. Carroll G, Hannan M (1989) Density dependence in the evolution of populations of newspaper organiza- tions. In C. Calhoun (ed.), Comparative Social Research, 12: 77-112. Greenwich, CT: JAI Press.

31. Nonaka I, Toyama R, Konno N (2000) SECI, Ba and leadership: A unified model of dynamic knowledge creation. Long Range Plan 33: 5-34.

32. Hedlund G (1994) A model of knowledge management and the N-form corporation. Strategic Manag J 15: 73-90.

33. Grant RM (1996) Toward a knowledge-based theory of the firm. Strategic Manag JW 17: 109-122.

34. Pisano G (1994) Knowledge, integration and the locus of learning: An empirical analysis of process development. Strategic Manag J 15: 85-100.

35. Zucker LG (1987) Institutional Theories of Organization. Ann Rev Socio 13:443-64.

36. Yang CW, Fang SC, Huang WM (2004) Isomorphic pressures, institutional strategies and knowledge creation in health care sector. Paper presented at the annual meeting of the Academy of Management, New Orleans.

37. Donna MD, Deed DL (2000) The impact of stock and flows of organizational knowledge on firm performance: An empirical investigation of the biotechnology industry. Strategic Manag J 20: 953-968.

38. Rynes SA, Bartunek JM, Daft RL (2001) Across the great divide: Knowledge creation and transfer between practitioners and academics. Acad Manag Rev 44: 340-355. 
39. Nahapiet J, Ghoshal S (1998) Social Capital, Intellectual Capital and the Organizational Advantage. Acad Manag Rev 23: 242-266.

40. De Boer M, Van Den Bosch FAJ, Volberda HW (1990) Managing organizational knowledge integration in the emerging multimedia complex. J Manag Stud 36: 379-398.

41. DiMaggio PJ (1991) Constructing an organizational field. In WW Powell \& PJ DiMaggio (Eds.), The new institutionalism in organizational analysis: 267-292.

42. Scott WR (1995) Institution: Institutional Theory and organizations. In W.R. Scott \& S. Christensen (Eds.), The Institutional Construction of Organizations: xi-xxii. Thousand Oaks, CA: Sage.

43. Child J (1972) Organizational structure, environment and performance: The role of strategic choice. Sociol 6: 1-22.

44. Elsbach KD, Sutton RI (1992) Acquiring organizational legitimacy through illegitimate action: A marriage of institutional and impression management theories. Acad Manag J 35: 699-738.

45. Ginzel LE, Kramer RM, Sutton RI (1992) Organizational Impression management as a reciprocal influence process: The neglected role of the organizational audience. In L.L. Cummings \& B.M. Staw (Eds.), Res Or- ganiz Behav 14: 227-266.

46. Oliver C (1997) The influence of institutional and task environment relationships on organizational perfor- mance: the Canadian construction industry. J Manag Stud 34: 99-124.

47. Nonaka I (1994) A dynamic theory of organizational knowledge creation. Organiz Sci 5: 14-37.

48. Kloot L (1997) Organizational learning and management control systems: responding to environmental change. Manag Account Res 8: 47-73.

49. Tsai W (2001) Knowledge transfer in intraorganizational networks: Effects of network position and absorptive capacity on business unit innovation and performance. Acad Manag J 44: 996-1004.

50. Robertson M, Scarbrough H, Swan J (2003) Knowledge creation in professional service firms: Institutional effects. Organ Stud 24: 831-857.

51. Thompson J (1967) Organizations in Action. New York: McGraw-Hill.

52. JCAHO (Joint Commission on the Accreditation of Healthcare Organizations). 1996. Accreditation Manual for Hospitals. Chicago: JCAHO.

53. Myer JW, Scott WR, Strange D (1983) Organizational Environments: Ritual and Rationality. Beverly Hils, CA: Sage.

54. Baum J, Oliver C (1991) Institutional linkages and organizational mortality. Admin Sci Quart 36: 187-218. 